\title{
Describing the Grass Inflorescence
}

\section{KELLY WAYNE ALLRED}

The world's biggest crop is grass. It is found nearly everywhere, from hot deserts to inside the Arctic Circle, and it covers more than a fifth of the land surface of the earth. More people eat grass or grass products than any other plant food. Range managers are often grass managers, as grasses are frequently the dominant prim-

Author is assistant professor, Department of Animal and Range Sciences, New Mexico State Univ., Las Cruces 88003.

The author wishes to acknowledge the helpful comments of Stephen L. Hatch and an anonymous reviewer.

This is Journal Article 914, New Mexico Agr. Exp. Sta., Las Cruces 88003.

Manuscript received April 21. 1981. ary producers of rangelands. Of all plant families, the Gramineae, or grass family, is undoubtedly the most important and most essential to man's existence.

In view of this, it seems imperative that we are able to communicate about grasses. Effective communication lies in a precise and uniform usage of terms, whereas ambiguity makes communication difficult or impossible. The recognition of this principle prompted the publication of $A$ Glossary of Terms Used in Range Management (Kothmann 1974) by the Society for Range Management.

Several years of teaching and assisting courses in agrostology have brought to light a disconcerting confusion in terminology 
about the grass inflorescence. Efforts to teach, and to lea m about grasses have been hampered by the lack of uniformity in terminology dealing with the grass inflorescence. For example, the Manual of the Grasses of the United States (Hitchcock 1951), probably the most consulted reference on grasses in the United States, uses the same term, raceme, to describe the different inflorescences of green sprangletop (Leptochloa dubia), St. Augustine grass (Stenotaphrum secundatum), semaphore grass (Pleuropogon spp.), silver bluestem (Bothriochloa saccharoides), and little bluestem (Schizachyrium scoparium). Conversely, for two grasses with almost identical inflorescences, tumble lovegrass (Eragrostis sessilispica) and tumblegrass (Schedonnardus paniculatus), the terms panicle and spike a re applied. Although the visual recognition and identification of a range grass may be independent of whatever terms we may use to describe that grass, the effective organization, correlation, storage, and retrieval of a body of knowledge in our minds depends on uniform description and precise terminology.

\section{Nature and Composition of the Grass Inflorescence}

To best understand the nature of the grass inflorescence, we must compare it to the inflorescence of other flowering plants and contrast the terminology of each.

As currently used for most flowering plants, an inflorescence is the flowering portion of a plant, or the arrangement of flowers on a floral axis (Abercrombie et al. 1960, Benson 1979, Gould 1968, Smith 1977). The term also originally referred to the sequence of flowering within a flower cluster, but this connotation is rarely emphasized. Based on the sequence of flowering, inflorescences are divided into two groups, indeterminate and determinate. Indeterminate inflorescences maintain an active meristem at the apex of the flowering shoot, and may continue to grow as long as conditions are favorable. This means the oldest (most mature) flowers will be found at the base of the floral axis (acropetal development). In determinate inflorescences the apical meristem differentiates a flower, and any further elongation of the primary flora axis is halted; the growth of the inflorescence is limited and the oldest flowers are found at the apex of the flowering shoot (basipetal development).

The terms spike, raceme and panicle, as used for nongrasses, apply to indeterminate inflorescences. In spikes and racemes, the flowers are sessile and pediceled, respectively, on the primary floral axis, and in panicles the flowers are borne on a secondary rebranched axis. It should be noted that this inflorescence terminology is based on flower arrangement. As such, a spikelet of grass is technically an inflorescence by itself: a small spike of essentially sessile flowers enclosed by bracts (paleas, lemmas, glumes). And, as in all "true" spikes, the sequence of maturation within the spikelet is from base to apex (acropetal).

Because of the similarity of flower and spikelet arrangement, the same terms spike, raceme, and panicle have been applied to the grass inflorescence. Grasses, however, generally exhibit a determinate growth pattern of the overall flowering shoot, with the most mature spikelets toward the apex and least mature toward the base (asipetal). The arrangement and maturation of spikelets (not flowers) are not properly referrable to spike, raceme, or panicle.

\section{Proposed Terminology for the Grass Inflorescence}

The grass inflorescence is a highly modified, complex structure, with a different ontogeny than the nongrass inflorescence. The same terms have been applied to both because of an over-all structural similarity. Rather than propose a new set of terms for either group, clarity and accuracy may be attained by precise definitions and uniform usage of terms. The terminology presented here is meant to be purely descriptive and does not attempt to classify inflorescences on the basis of homology or derivation. Rickett (1944) presents an excellent review of the problems associated with inflorescence classification. For the grass inflorescence, I propose we adopt the following restrictions. (These guidelines represent a synthesis of my own proposals with ideas gleaned from Gould 1968, Hitchcock 1951, Benson 1979, and Smith 1977.):

1. The grass inflorescence is delimited at the base by the node of the uppermost leaf. There are no leaves or bracts (except those of the spikelet) present within an inflorescence. This means that little bluestem (Schizachyrium scoparium) and broomsedge bluestem (Andropogon virginicus, Fig. 1) produce many individual flowering segments, each subtended by a leaf (the spathe), and each a separate inflorescence clustered with the others.

2. For descriptive purposes, inflorescence terminology for the grasses will be based upon the arrangement of spikelets rather than flowers. As has been noted, the spikelet itself is technically an inflorescence.

3. The terms panicle, raceme, and spike will continue to be applied, but with the following definitions.

Spike. (Fig. 2). All inflorescences where the spikelets are sessile upon the central axis. Most members of the tribe Triticeae produce this type of inflorescence, as well as Hilaria, Lolium, and Microchloa.

Raceme. (Fig. 3). All inflorescences where the spikelets are pediceled, or stalked, upon the central axis. This is relatively rare in grasses, but characteristic of Pleuropogon, Brachypodium, some Danthonia, and some depauperate plants of Bromus, Festuca, and Avena.

Panicle. (Fig. 4). All inflorescences where the spikelets are not borne on the main axis of the inflorescence, but are borne on branches. This will include most grasses. Obviously, the variation is great enough that descriptive adjectives will be needed to describe accurately the panicle (see \#4 below). The inflorescences of Andropogon, Bouteloua, Chloris, most Eragrostis, and most Poa will be panicles.

4. Inflorescences will not be compound, that is, an inflorescence type will not be composed of other inflorescence types. Rather, descriptive adjectives will be used to qualify the variation pattern. Thus, the inflorescence of green sprangletop (Leptochloa dubia, Fig. 5) will best be described as "a panicle of racemose primary branches," rather than "a panicle of racemes." The terms raceme and spike will not be used for part of an inflorescence; this eliminates a major source of confusion among students. Likewise, blue grama (Bouteloua gracilis Fig. 6) will be "a panicle of spicate primary branches," and hooded windmillgrass (Chloris cucullata, Fig. 7) "a panicle of digitate spicate branches." Although it may appear complicated at first glance, the use of modifiers such as spicate, racemose, unbranched, digitate, whorled or verticillate, and pectinate to describe the variations of the panicle adds clarity and precision to the terminology.

5. Occasionally, a main axis (Hordeum, Schizachyrium, Fig. 8), or a branch (Andropogon, Bothriochloa) will bear both sessile and pediceled spikelets. In the first instance, the inflorescence arbitrarily will be termed a spicate raceme. In the second, since the inflorescence is of the panicle type, the description may be "a panicle of racemose branches."

Pohl (1968) uses the term rame to describe such intermediate conditions. He defines a rame as (p. 242) "an inflorescence branch which bears some stalked and some sessile spikelets, as in Andropogon and Hordeum." This is clear enough, except for the examples. The Hordeum inflorescence contains no branches (as specified in the definition), is properly termed a spicate raceme, and should be deleted from the definition. We must also understand that Andropogon is delimited in the strict sense, excluding Schizachyrium, which was formerly treated as a section of Andropogon. As with Hordeum, the inflorescence of Schizachyrium contains no branches and is a spicate raceme. With these emendations to the definition, the term rame may be defined as an inflorescence branch that bears repeating pairs of sessile and pedicellate spikelets. The term is particularly useful when applied to paniculate inflorescences of many Andropogoneae; ie., they are composed of rames. 

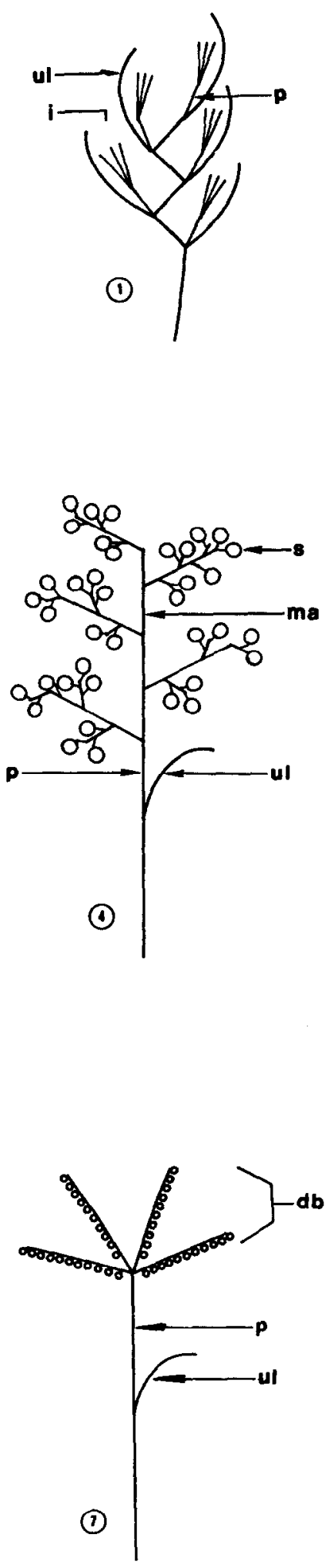
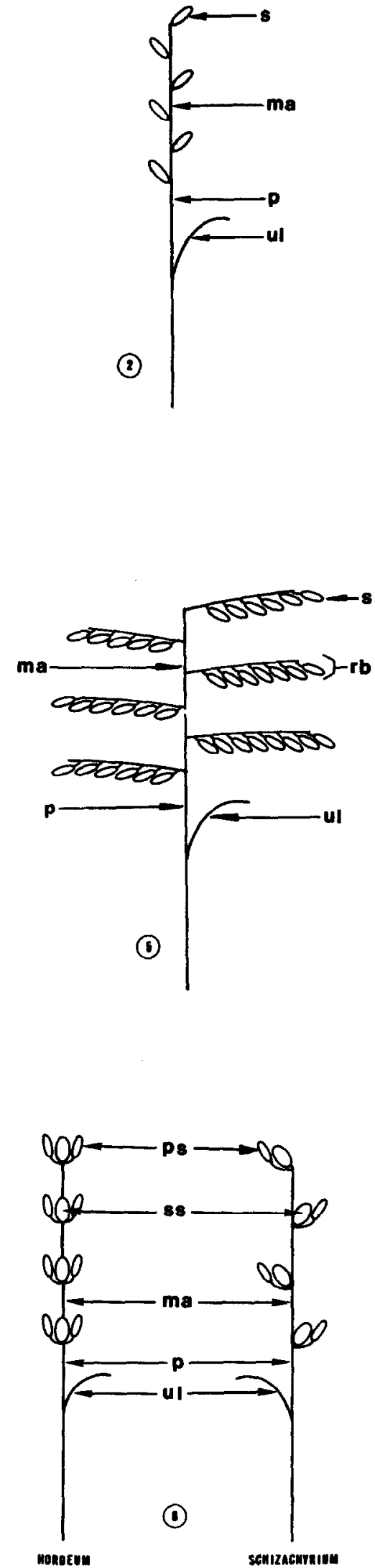
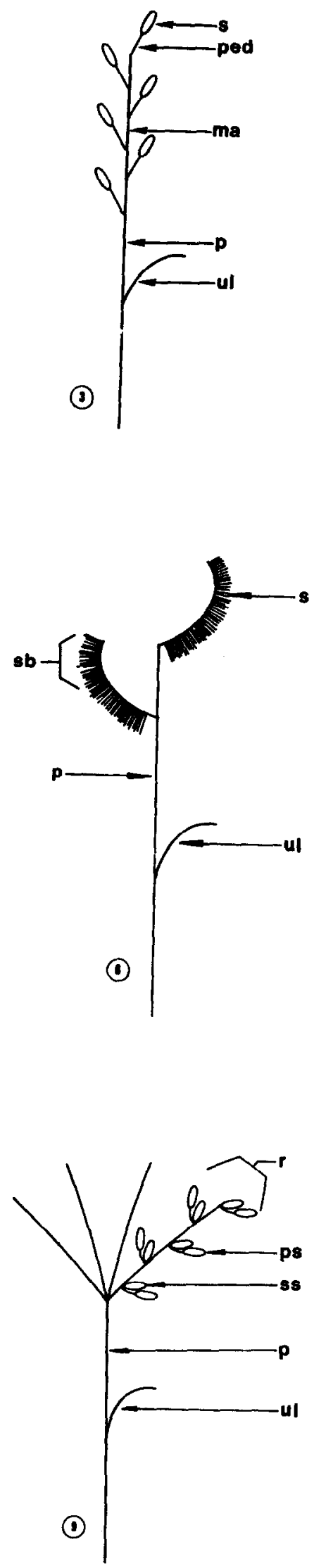

Figs 1-9. Diagrammatic representations of selected grass inflorescences. $d b=$ digitate primary branches. $i=$ inflorescence. ma $=$ main axis. $p=$ peduncle. ped = pedicel. $p s=$ pediceled spikelet. $r=$ rame. $r b=$ racemose primary branch $s=$ spikelet. sb $=$ spicare primary branch. ss $=$ sessile spikelet. ul $=$ uppermost leaf delimiting the inflorescence. (Fig. 1) Chustered inflorescences of Andropogon virginicus. (Fig. 2) Generalized spike inflorescence. (Fig. 3) Generalized raceme inflorescence. (Fig. 4.) Generalized panicle inflorescence. (Fig. 5) Panicle of green sprangletop. (Fig. 6) Panicle of bhue grama. (Fig. 7) Panicle of hooded windmillgrass. (Fig. 8) Spicate racemes of Hordeum and Schizachyrium. (Fig. 9) Panicle of big bluestem. 
6. The term rachis (rhachis) will refer only to the central axis of an inflorescence, whether spike, raceme, or panicle, but not to the axis of a branch of the inflorescence. This is consistent with its usage when applied to leaves. Therefore, Hordeum will disarticulate in the rachis, and Bothriochloa in the joints (or internodes) of the rame.

7. The inflorescences of several grasses will represent a reduction from a more developed stage. As has been noted, normally paniculate inflorescences of Bromus and Avena are occasionally reduced to racemes in depauperate plants. Likewise, it is not uncommon to find just a single spicate branch in blue grama or in eastern gamagrass (Tripsacum dactyloides), in which two or three are typical. Reductions such as these pose no problems in terminology, as it is usually evident that such inflorescences represent atypical forms. In blue grama with a single branch, for instance, it is clear that the spikelet-bearing structure is a lateral branch and is not the central axis or rachis. The inflorescence can be described without confusion as "a panicle of spicate primary branches, occasionally reduced to a single branch."

Consistent patterns in reduction are also easily described. In the Andropogoneae tribe a common inflorescence is the spicate raceme, with both sessile and pediceled spikelets on the rachis, as in Schizachyrium, Elyonurus, Trachypogon, and Heteropogon. This has most likely resulted from the consistent reduction of all branches except one. The remaining branch is generally not a lateral structure as in blue grama, but represents the continuation of the central axis, and the resulting inflorescence may be termed a raceme.
It is also well to keep in mind that the variation present in grass morphology, whether regarding inflorescences, ligules, spikelets, or other features, very often exceeds the limits imposed by our efforts at description and categorization. We will certainly encounter conditions that do not fit clearly into our categories. These are relatively infrequent, however, and the main patterns are clear.

Careful use of terminology in describing the grass inflorescence will lead to a clear understanding and a correlation of the different types found in grasses. Spikes will be found in most Triticeae, panicles with spicate branches in most Chlorideae and many Eragrosteae, and rames in the Andropogoneae. It is hoped that teaching efforts will be aided by the discussion presented here, and that communciation about grasses can be clear and useful.

\section{Literature Cited}

Abercrombie, M., C.J. Hickman, and M.L. Johnson. 1960. A Dictionary of Biology. Penguin Books, Harmondworth, England, 251 p.

Benson, L. 1979. Plant Classification. 2nd ed. D.C. Heath and Co., Lexington, Mass. 901 p.

Gould, F.W. 1968. Grass Systematics. McGraw-Hill, New York. 382 p.

Hitchcock, A.S. 1951. Manual of the grasses of the United States. Rev. by Agnes Chase. U.S. Dep. Agr. Misc. Pub. 200. 1051 p.

Kothmann, M.M., Chairman, Range Term Glossary Committee. 1974. A Glossary of Terms Used in Range Management. Soc. Range Manage. Denver, Colo. $36 \mathrm{p}$.

Pohl, W. 1968. How to Know the Grasses. Wm. C. Brown Co., Dubuque, lowa. 244 p.

Rickett, H.W. 1944. The classification of inflorescences. Bot. Rev. 10:187231.

Smith, J.P. Jr. 1977. Vascular Plant Families. Mad River Press, Eureka, Calif. 320 p. 